\title{
A new face to BJID: perspective for the near future
}

The Brazilian Journal of Infectious Diseases (BJID), an official publication of the Brazilian Society of Infectology, is entering its 14th year of life. During this period of time, the journal has became one of the most influential scientific publication in the field of infectious diseases, in Brazil, which can be measured by the increasing number of papers received from many scientists from different countries and its indexing in most existing databases, including the recent inclusion in ISI-Web of Science-Science Citation Index Expanded and Journal Citation Reports (JCR): Science Edition, the most valued database systems for evaluation of scientific citation impact.

In 2010, many other changes will be introduced in BJID: first, after a long-term, well succeed partnership with Contexto, the publishing company since BJID creation, the journal will be published by Elsevier Editora Ltda, a well-known, prestigious editor of books and scientific journals worldwide. This initiative will give BJID a greater international visibility, and certainly will increase the number and quality of submitted papers. Second, we will soon release a special version of BJID, named BJID-EMC/CME (Educação Médica Continuada/Continuous Medical Education), which will also have 6 editions/year, with focus on state-of-the-art reviews, and intends to provide BJID readers with a tool for medical education. We plan to provide some question at the end of each review, to serve as CME evaluation, giving the reader the chance to use the gained points for the Brazilian Society of Infectology Evaluation Board. The publication will be only in Portuguese, to facilitate the access to a larger number of Brazilian readers, and will be available both in printed as well as in online editions.

A huge effort is being made to reduce the length of reviewing process, to result in a faster response to authors, a quicker publication of accepted papers, and a rapid definition on the rejected manuscripts. In addition, the completely new official BJID website has a friendlier interface, allowing authors an easier submission of their manuscripts and a follow up of all the steps involved in the revision process.

Finally, the increasing number of manuscripts received in the last year led us to decrease the proportion of accepted ones. This process will have two expected consequences: an increase in the quality of published papers and the need to plan a move towards a monthly edition of BJID in a near future. These changes will result in an even stronger, high-quality publication for our readers. 